cabs in India are smoke free. However, large majority of the cab drivers are addicted to tobacco.

The study objectives were to measure cab driver's knowledge and opinion about tobacco, understand pattern of tobacco usage, provide assistance in quitting tobacco, perform oral cancer screening, measure effectiveness of smoking ban in cabs and understand perceptions of cab drivers to ban.

Methods $400 \mathrm{cab}$ drivers in Mumbai were enrolled and interviewed. They were offered health education, oral cancer screening and tobacco cessation assistance at regular intervals over a year.

Results 64\% cab drivers used tobacco, mainly in smokeless forms (80\%). 94\% intended to quit, $66 \%$ had made previous quit attempts and 70\% expressed need of assistance for quitting tobacco. $62 \%$ had displayed a No Smoking sign in their $\mathrm{cab}$ and $75 \%$ expressed full compliance by passengers to the ban. $30 \%$ of cab drivers had oral precancerous lesions and one cab driver was diagnosed with invasive oral carcinoma. $32 \%$ of cab drivers had quit tobacco by the end of nine months and $36 \%$ cab drivers had reduced their tobacco consumption.

Conclusions Smoke free laws are important to reduce exposure of cab drivers to second hand smoke. However, many $\mathrm{cab}$ drivers are themselves addicted to tobacco and hence need assistance for quitting. We demonstrated the successful implementation of tobacco control and cessation program to support the Smoke Free Laws.

\section{IMPLEMENTING THE OCCUPATIONAL SAFETY AND HEALTH POLICY IN SENEGALESE COMPANIES: CASE STUDY OF THE NATIONAL WATER COMPANY OF SENEGAL (SONES)}

${ }^{1}$ Matam Dia Tall, ${ }^{2}$ Mourtadhoi Asnaya. 'Sones's Medical Centre, Dakar, Senegal; ${ }^{2}$ Vocational Training School, Dakar, Senegal

\subsection{6/oemed-2018-ICOHabstracts.890}

Introduction The implementation of the safety and health policy in Senegalese companies remains minimal or no existent. The objective is to study and evaluate the safety and health activities of SONES from 2011 to 2015.

Methodology and materials It is a five-year retrospective study (2011-2015) to assess the implementation of the safety and health policy of SONES. We included all existing health and safety initiatives. Our data sources were: the annual reports of the health and safety at work committee and the Medical Centre, questionnaires. Data were collected from the Excel file and analysed using the Epi info 3.5.1 software.

Results and discussion SONES has developed a health and safety policy and has an autonomous Medical Centre for 112 workers (96\% are permanent). Within the framework of the occupational hygiene and safety committee established since 2011, 79\% of the actions planned were carried out during the five years. There are stressors at SONES and they are linked to the workload, which is heavy and varied.

Conclusion The evaluation of occupational safety and health policy implemented by SONES from 2011 to 2015, has revealed the existence of occupational hazards mainly heavy load; psychosocial factors and ambient constraints. However, the management has taken several prevention control measures to improve working conditions.

\section{5 \\ OCCUPATIONAL DISEASE HAZARD FACTORS INVESTIGATION AND RISK ASSESSMENT IN ONE HOVERCRAFT MANUFACTURING ENTERPRISE}

Guang Zheng KePing Wang. Shanghai institute of Occupational Disease for Chemical Industry

\subsection{6/oemed-2018-ICOHabstracts.891}

Introduction Risk assessment can provide the technology measurement to decrease the accident. China has issued two national occupational health standard- 'Classification of occupational hazards at workplaces' (GBZ/T229-2010) and' Classification for hazards of occupational exposure to toxicant' (GBZ/T230-2010) in 2010. According to the toxicant exposure standard, calculating the hazards level, exposure to toxicant and labour intensity of workers can assess the exposure risk of workers. This study investigates and assesses the occupational disease hazard factor in the Hovercraft manufacturing enterprise.

Method To adopt the occupational health investigation method, detection and testing method and risk assessment method to measure and analyses the concentration or intensity of occupational hazards in workplace, and develop the qualitative and quantitative analysis according to the national occupational health standard- 'classification of occupational hazards at workplaces' and 'classification for hazards of occupational exposure to toxicant'.

Results On the basis of Chinese national standard 'Specifications of air sampling for hazardous substances monitoring in the workplace', concentration of ten occupational hazards factors which are Fibrous glass dust, Welding fume, Styrene, Acetone, Ozone, Carbon monoxide, Nitrogen dioxide, Sulfur dioxide, Epichlorohydrin, Manganese are detected under the national standard. The highest toxicant hazards index of Sulfur dioxide and Epichlorohydrin is 59, and the lowest toxicant hazards index of Nitrogen dioxide is 40 in the 10 occupational hazards of this factory.

Conclusion There are higher occupational hazards risk in glueinggluing post of Boat manufacturing. The hazard level of styrene and epichlorohydrin is highest in the 10 occupational hazards.

\section{EXPANSION OF OCCUPATIONAL HEALTH TO INCLUDE ENVIRONMENTAL AND COMMUNITY HEALTH: A PHILIPPINE EXPERIENCE}

Joselito L Gapas*. First Philippines Holdings Corporation, Pasig City, Metro Manila, Philippines

\subsection{6/oemed-2018-ICOHabstracts.892}

Introduction Occupational health $(\mathrm{OH})$ in Philippines private sector companies is changing, being driven by awareness that promotion and protection of worker's health is a good investment. Challenges include limited $\mathrm{OH}$ competency, limited regulatory compliance, and low appreciation of proactive and risk based approach. The First Philippine Holdings Corporation $(\mathrm{FPH})$ is involved in energy generation, real estate, construction, manufacturing, and health care. Since 2011, FPH began developing a risk-based $\mathrm{OH}$ management system. The Philippine Environmental Impact System (EIS) System requires environmentally critical projects to conduct an environmental and health Impact assessment including regular assessment risk assessment and impacts to workers and host communities. 